\title{
Direct Instruction by an Experienced Surgeon Can Shorten the Learning Curve for Laparoscopic-Assisted Distal Gastrectomy
}

\author{
Masashi Takemura ${ }^{1,2^{*}}$, Katsuyuki Mayumi ${ }^{1}$, Takashi Ikebe ${ }^{1}$, Sinya Tanimura ${ }^{2,3}$ \\ ${ }^{1}$ Department of Surgery, Gohshi Hospital, Hyogo, Japan; ${ }^{2}$ Department of Gastrointestinal Surgery, Osaka City General Hospital, \\ Osaka, Japan; ${ }^{3}$ Department of Gastrointestinal Surgery, Cancer Institute Ariake Hospital, Tokyo, Japan. \\ Email: jumbo99_2002@yahoo.co.jp
}

Received April $8^{\text {th }}, 2013$; revised May 15 ${ }^{\text {th }}, 2013$; accepted May 24 $4^{\text {th }}, 2013$

Copyright (C) 2013 Masashi Takemura et al. This is an open access article distributed under the Creative Commons Attribution License, which permits unrestricted use, distribution, and reproduction in any medium, provided the original work is properly cited.

\begin{abstract}
Aim: Laparoscopy-assisted distal gastrectomy (LADG) with regional lymph node dissection is a treatment option for patient with early gastric cancer. However, LADG is a technically complex and advanced procedure, which is challenging for inexperienced surgeons. In this report, we retrospectively evaluated the learning curve for LADG of a single surgeon with no previous experience in LADG and the usefulness of direct instruction by a surgeon experienced in LADG in shortening the learning curve. Patients and Methods: This study was analyzed 80 consecutive patients, who underwent LADG by a single surgeon (first assistant in 10 cases and operator in 70 cases) between January 2008 and December 2012. Patients were divided into 3 sequential groups of 10 (training period), 30 (learning period), and 40 (operating period) cases in each group. Median operation time and estimated blood loss for these 3 groups were determined. Other learning indicators, including transfusion requirement, postoperative complications, number of lymph node harvested, and rate of conversion open gastrectomy, were also evaluated. Results: During the training period, median operation time and estimated blood loss were $219.5 \mathrm{~min}$ and $83.0 \mathrm{ml}$, respectively. During the learning period, the operation time was significantly longer than that of training period. In the operating period, the operation time was significantly lesser than that during the learning period. However, the operation time was not different from that during the training period and reached a plateau. The estimated blood loss during the operating period was significantly lesser than that during the learning period. The difference in the number of lymph nodes retrieved between each group was not significant. Conclusions: Direct instructions by an experienced surgeon can decrease the number of cases required for learning. Because LADG is technically more complex than other laparoscopic procedures, standardization of LADG and an effective training system for performing it should be established.
\end{abstract}

Keywords: Laparoscopic-Assisted Distal Gastrectomy; Learning; Training System

\section{Introduction}

Gastric cancer is the most common malignancy in Japan, and gastrectomy with regional lymph node dissection is still the standard treatment for patients with resectable gastric cancer [1,2]. Laparoscopy-assisted gastrectomy (LADG) for early gastric cancer has evolved and become rapidly accepted in Japan since it was first reported by Kitano et al. [3-5]. LADG with regional lymph node dissection has recently become a treatment option for patients with early gastric cancer [6,7]. LADG has many advantages over conventional open distal gastrectomy

*Corresponding author.
(ODG): less invasiveness, blood loss, and postoperative pain, faster recovery, shortened hospital stay, and better cosmetic results [8-11]. Moreover, because long-term survival rates in patients with early gastric cancer after LADG have been reported to be similar to those of ODG [12,13], many Japanese surgeons have adopted a laparoscopic approach to distal gastrectomy. However, LADG is a technically complex and advanced procedure, which is challenging for inexperienced surgeons; therefore, surgeons need to overcome a learning curve.

Although many reports have presented the various surgical technique of LADG, few reports have described the learning curve associated LADG [14-18], and none has 
shown whether direct instructions by a surgeon experienced surgeon in LADG can shorten the learning curve. In this report, we retrospectively evaluated the learning curve for LADG of a single surgeon with no prior experience in performing LADG. We also evaluated the usefulness of direct instructions by a surgeon experienced in LADG in shortening the learning curve.

\section{Patients and Methods}

This study was based on 80 gastric cancer patients on whom LADG was performed at the Department of Gastrointestinal Surgery, Osaka City General Hospital, Osaka, Japan and the Department of Surgery, Gohshi Hospital, Hyogo, Japan. At these hospitals, a single surgeon participated in 80 cases of LADG (10 as a first assistant and 70 as an operator) consecutively between January 2008 and December 2012. In the initial 10 cases (training period), an experienced surgeon (ST) directly instructed the inexperienced surgeon (MT), who was a first assistant for the procedures, in the technique of laparoscopic gastrectomy. ST had already performed over 600 cases of laparoscopic gastrectomy for early gastric cancer [6], and MT had experienced open gastrointestinal surgery among 15 years and no prior experience performing LADG. MT had operated open gastrictomy over 200 cases. After 10 cases, as a first assistant, MT performed his first case of LADG as the operator followed by 70 consecutive cases. $\mathrm{KM}$ and TI were participate in these operations at assistant or camera holder.

Preoperative staging was determined by gastrofiberscopy, barium swallowing study, abdominal computed tomography, and assessment of tumor markers including carcinoembryonic antigen (CEA) and carbohydrate antigen 19-9 (CA 19-9). Eleven patients had previously undergone endoscopic submucosal resection and diagnosed with submucosal invading tumor with recommendation to undergo salvage gastrectomy. Patients with cancer in other organs or severe comorbidities that obviated major abdominal operations (liver cirrhosis, renal dysfunction, or cardiovascular disease) were excluded from this study. The LADG patients were limited to those in whom there was clinical invasion of the mucosa, submucosa, or muscularis propria of the stomach (cT1 or cT2). Moreover, clinical lymph node metastasis was limited within perigastric node ( $\mathrm{cN} 0$ or $\mathrm{cN} 1)$. The clinical and pathological staging and definition of lymph nodes were principally based on the Japanese Classification of Gastric Carcinoma, 3rd English edition [19].

To define the learning curve, the 80 patients were divided into 3 sequential groups of 10 (training period), 30 (learning period), and 40 (operating period) cases in each group. Median operation time and blood loss for each group were determined. Other learning indicators, inclu- ding transfusion requirement, number of lymph nodes harvested and rate of conversion conventional open gastrectomy, were also evaluated for statistical significance. To assess postoperative outcomes, postoperative complications above Clavien-Dindo classification grade II and length of postoperative hospital stay were analyzed [20].

Statistical analysis was performed using the KruskalWallis test with post hoc test (Dunn's multiple comparison test) for continuous variables, and the $\chi$ square test for categorical variables. Data were expressed as median and range. For all statistical analyses, $P<0.05$ was considered statistically significant.

\section{Surgical Procedure}

Under general anesthesia, the patient was placed supine in reverse Trendelenburg position. A 12-mm infraumbilical trocar was inserted using the open method, and 5 trocars (two 12-mm trocars and three 5-mm trocars) were inserted under direct laparoscopic assistant as shown in Figure 1. A telescope (45 degree, $10 \mathrm{~mm}$ ) was inserted through the infraumbilical trocar. Under pneumoperitoneum of 8 - $10 \mathrm{mmHg}$, the greater omentum was divided beginning at a point $3-4 \mathrm{~cm}$ from the gastroepiploic arcade and extending toward the lower pole of the spleen, which included No. 4d and 4sb lymph nodes, using a Harmonic scalpel.

After completion of the omentectomy, the root of the right gastroepiploic vein and artery were isolated and double-clipped (Figure 2(a)). The right gastric artery was then exposed and divided at its origin using clips (Figure 2(b)). The duodenum was transected $1 \mathrm{~cm}$ distal from pyrolus ring using an Endo-GIA Ultra Universal Stapler (Tyco Health Care, Norwalks, CT). After resection of the lesser omentum up to the esophagogastric

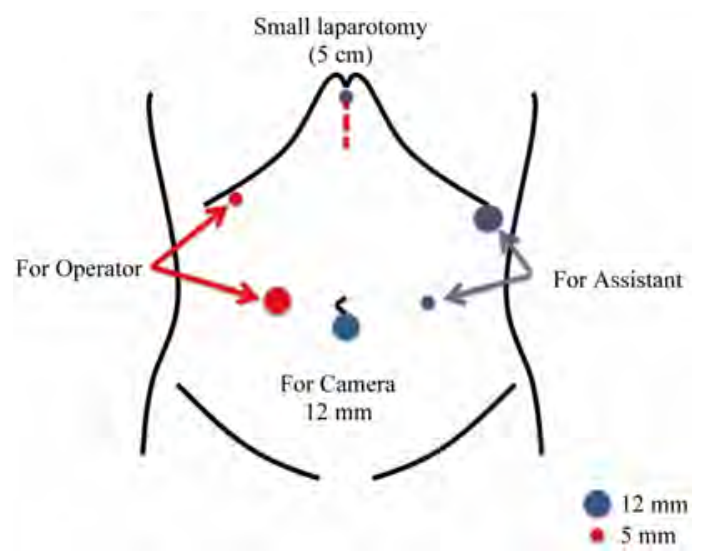

Figure 1. Trocars location of our procedure. A 12-mm infraumbilical trocar was inserted using the open method, and 5 trocars (two 12-mm trocars and three 5-mm trocars) were used. 


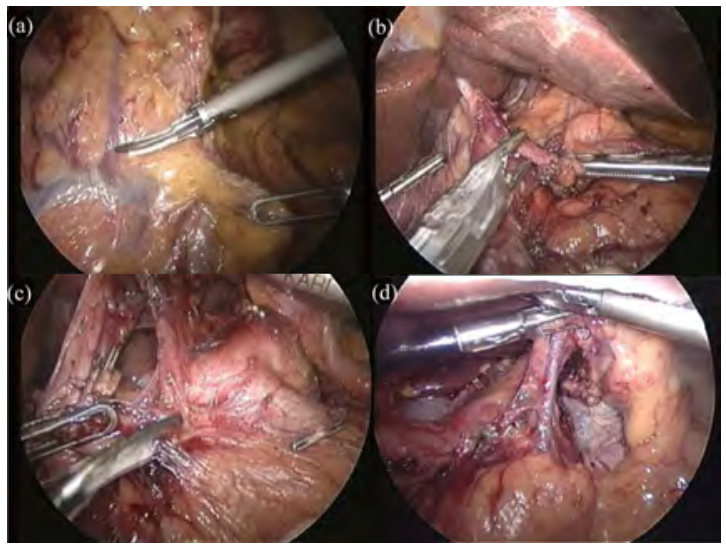

Figure 2. Operative views of laparoscopy-assisted distal gastrectomy. (a) After completion of the omentectomy, the root of the right gastroepiploic vein and artery were isolated and double-clipped; (b) The right gastric artery was then exposed and divided at its origin using clips; (c) After resection of the lesser omentum up to the esophagogastric junction, the lymph nodes along the common hepatic artery were dissected; (d) The left gastric vein and the root of the left gastric artery were double-clipped and divided. And the lymph nodes along the left gastric artery were dissected.

junction, the No. 8a lymph nodes (those along the common hepatic artery) were dissected using Harmonic scalpel (Figure 2(c)). The left gastric vein and the root of the left gastric artery were double-clipped and divided. The No. 7 lymph nodes, along the left gastric artery (Figure 2(d)), the No. 9 nodes, around the celiac artery, and the No.11p nodes, at the proximal part of the splenic artery, were dissected.

The perigastric lymph nodes along the lesser curvature up to the esophagogastric junction were dissected from proximal to distal (No. 1 and No. 3 nodes). The perigastric lymph nodes along the greater omentum were also dissected from distal to proximal side. This completed the intracorporeal lymph node dissection.

A 5-cm upper median skin incision was made from the substernal angle, for Billroth I reconstruction or Rouxen-Y reconstruction through an antecolic route. The distal two-thirds of the stomach was resected using a linear stapler (Endo-GIA Ultra). Billroth I gastroduodenostomy was performed using 3 linear staplers (triangle suture), and Roux-en-Y gastrojejunostomy with side-to-side jejunojejunostomy was also performed using a linear stapler. Irrigation of the operative field was performed to ensure satisfactory hemostasis under pneumoperitoneum. Each trocar was removed and the incisions closed after a closed-suction drain had been placed around the anastomosis.

\section{Results}

Patients' demographic data are listed in the Table 1. In this study, 53 men and 27 women, with median age of 64.0 years (range 36 - 89 years) were included. Median BMI was $22.1 \mathrm{Kg} / \mathrm{m}^{2}$. Forty-seven patients had preoperative comorbidities, and none of them required conversion to open gastrectomy. Median operation time was 234.5 min (range 146 - $417 \mathrm{~min}$ ), and median estimated blood loss was $68.5 \mathrm{ml}$ (range 5 - $500 \mathrm{ml}$ ). The median number of lymph nodes retrieved was 27 (range 9 - 81). Postoperative complications occurred in 7 patients, including small-bowel obstruction in 3, pancreas-related infection in 2, cholecystitis in 1, and intra-abdominal abscess in 1. None of the patients developed anastomotic leakage. All these complications were treated conservatively. Forty patients were diagnosed with pathological mucosal lesion, 30 with submucosal lesion, and 10 had tumor invasion into musclaris propria or deeper. Eight patients were diagnosed with pathological lymph node metastasis, 3 as pN1 and 5 as pN2.

The median postoperative hospital stay was 13.0 days (range 7 - 84), and no patient died during the hospital stay in this cases series.

\section{Learning Curve of Surgeon}

Learning curve of the surgeon (MT) was evaluated. A comparison of the clinical factors of the 3 groups is shown in Table 2. There were no significant differences in Age, Gender, location of tumor, frequency of postoperative complications, and duration of hospital stay. Figures 3 and $\mathbf{4}$ are box plots of operation time and estimated blood loss for each group. During the training period, median operation time was 219.5 min. Median operation time of the 30 cases performed during the learning period was significantly longer than that performed during the training period. However, the operation time in the operating period was significantly lesser than that during the learning period, and not different from that of the training period, eventually plateauing.

During the training period, the estimated blood loss was $83.0 \mathrm{ml}$. Estimated blood loss during the operating period was significantly lesser than that during the learning period, but the difference in the number of lymph nodes retrieved between groups was not significant (Figure 5).

\section{Discussion}

The incidence of gastric cancer has decreased gradually but remains high in Japan. However, with the development of diagnostic modalities such as narrow-band imaging in gastric fiberscopy, the incidence of early stage among gastric cancer is increasing [21,22]. Quality of life post operation is important for patients with early gastric cancer because they have a better postoperative 

Laparoscopic-Assisted Distal Gastrectomy

Table 1. Patients’ demographic data.

\begin{tabular}{|c|c|c|c|}
\hline & & Number or Median & (Range) \\
\hline Age & (Year) & 64.0 & $(36-89)$ \\
\hline Gender (n) & (Male/Female) & $53 / 27$ & \\
\hline BMI & $\left(\mathrm{Kg} / \mathrm{m}^{2}\right)$ & 22.1 & $(13.6-35.4)$ \\
\hline \multirow[t]{2}{*}{ Location of tumor (n) } & Middle third & 53 & \\
\hline & Lower third & 27 & \\
\hline \multirow[t]{2}{*}{ Preoperative ESD (n) } & Yes & 11 & \\
\hline & No & 69 & \\
\hline \multirow[t]{2}{*}{ Preoperative morbidities (n) } & Yes & 47 & \\
\hline & No & 33 & \\
\hline \multirow[t]{2}{*}{ Type of reconstruction (n) } & Roux-Y & 69 & \\
\hline & Billroth I & 11 & \\
\hline Operation time & $(\min )$ & 234.5 & $(146-417)$ \\
\hline Blood loss & $(\mathrm{ml})$ & 68.5 & $(5-500)$ \\
\hline Blood transfusion & & 0 & \\
\hline Number of retrieved nodes & (number) & 27 & $(9-81)$ \\
\hline \multirow[t]{4}{*}{ Pathological depth of tumor invasion (n) } & pT1a & 40 & \\
\hline & pT1b & 30 & \\
\hline & pT2 & 5 & \\
\hline & pT3 & 5 & \\
\hline \multirow[t]{3}{*}{ Pathological lymph node metastasis (n) } & pN0 & 72 & \\
\hline & $\mathrm{pN} 1$ & 3 & \\
\hline & $\mathrm{pN} 2$ & 5 & \\
\hline \multirow[t]{6}{*}{ Pathological staging (n) } & IA & 69 & \\
\hline & IB & 4 & \\
\hline & IIA & 2 & \\
\hline & IIB & 2 & \\
\hline & IIIA & 2 & \\
\hline & IIIB & 1 & \\
\hline \multirow[t]{2}{*}{ Lymphatic invasion (n) } & Positive & 13 & \\
\hline & Negative & 67 & \\
\hline \multirow[t]{2}{*}{ Venous invasion (n) } & Positive & 7 & \\
\hline & Negative & 73 & \\
\hline \multirow[t]{4}{*}{ Postoperative complications (n) } & Small bowel obstruction & 3 & \\
\hline & Pancreas related infection & 2 & \\
\hline & Cholecystitis & 1 & \\
\hline & Intraabdominal abscess & 1 & \\
\hline Hospital stay & (days) & 13.0 & $(7-84)$ \\
\hline
\end{tabular}


Table 2. Comparison of the clinical factors of three groups.

\begin{tabular}{|c|c|c|c|c|c|}
\hline & & $\begin{array}{l}\text { Trainee period } \\
\qquad(\mathrm{n}=10)\end{array}$ & $\begin{array}{l}\text { Learning period } \\
\qquad(\mathrm{n}=30)\end{array}$ & $\begin{array}{l}\text { Operator period } \\
\qquad(\mathrm{n}=40)\end{array}$ & $P$ value \\
\hline Age (year) & (median (range)) & $65.0(53-78)$ & $62.5(36-82)$ & $64.5(42-89)$ & 0.733 \\
\hline \multirow[t]{2}{*}{ Gender (n) } & Male & 7 & 19 & 26 & 0.929 \\
\hline & Female & 3 & 11 & 14 & \\
\hline BMI $\left(\mathrm{Kg} / \mathrm{m}^{2}\right)$ & (median (range)) & $20.3(17.9-30.5)$ & $23.6(17.5-35.4)$ & $21.6(13.6$ - 28.4) & 0.015 \\
\hline \multirow[t]{2}{*}{ Location of tumor (n) } & Middle third & 7 & 19 & 27 & 0.903 \\
\hline & Lower third & 3 & 11 & 13 & \\
\hline \multirow[t]{2}{*}{ Postoperative complications } & Yes & 1 & 3 & 3 & 0.925 \\
\hline & No & 9 & 27 & 37 & \\
\hline Hospital stay (day) & (median (range)) & $14.0(12-27)$ & $12.0(8-38)$ & $13.0(7-84)$ & 0.280 \\
\hline
\end{tabular}

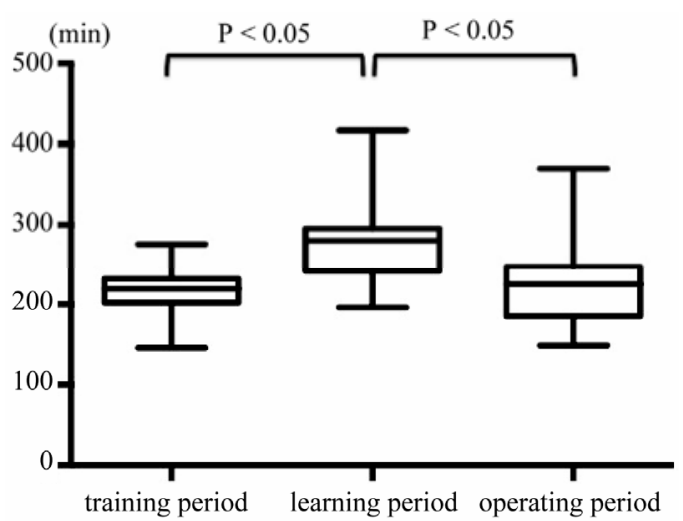

Figure 3. Comparison of operation time in each group. Median operation time during the learning period was significantly longer than that during the training period. However, the operation time in the operating period was significantly lesser than that during the learning period.

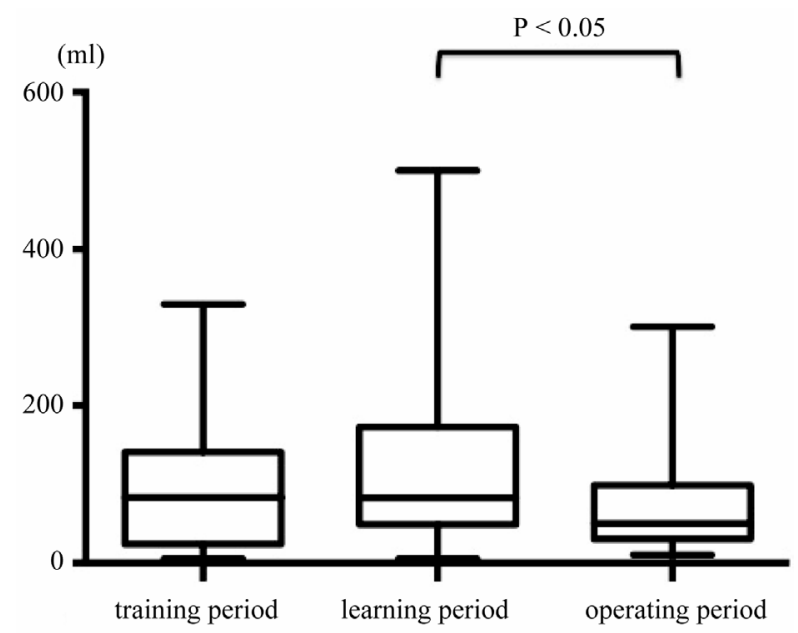

Figure 4. Comparison of estimated blood loss in each group. Estimated blood loss during the operating period was significantly lesser than that during the learning period.

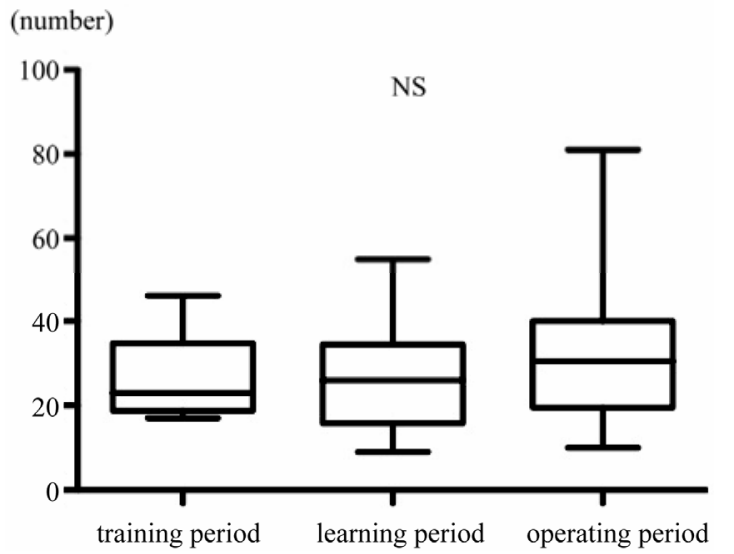

Figure 5. Comparison of the number of lymph nodes retrieved in each group. The difference in the number of lymph nodes retrieved between groups was not significant.

prognosis [23]. LADG is widely performed for early gastric cancer in Japan since its introduction by Kitano et al. [3-6]. However, LADG is technically a more complex operation compared with other laparoscopic procedures and still in the development phase.

Because laparoscopic gastrectomy has been reported to have substantial advantages over conventional operations, such as less postoperative pain, faster recovery, and better cosmetic results, many gastric surgeons have a high level of interest in learning the technique [8-11]. However, thus far there have been few published descriptions on the learning process associated with LADG [14-18]. Kang et al. [14] reported that progression along the learning curve as represented by decreased operation time is more apparent in the first 20 cases of LADG than in the first 20 cases of ODG, but surgeons reached a plateau in operation time after performing 50 LADG cases. In another report, Kim et al. [15] analyzed the data of 90 consecutive patients with early gastric cancer who un- 
derwent LADG with systemic lymphadenectomy. They found that surgeons reached the first plateau in operation time (230 - $240 \mathrm{~min})$ after 10 cases and a second plateau (<200 min) after 50 cases. In Japan, Kunisaki et al. [16] performed a comparative study of 100 patients who underwent LADG and 67 patients who underwent ODG. After 60 LADG cases, the operation time and duration of hospital stay in the LADG group were not significantly different from those in the ODG group. These studies suggested that 50 - 60 cases are required to learn to perform LADG. However, many factors affect the case volume required for learning, such as hospital case volume, standardization of the procedure, and previous experience of surgeons and surgical teams performing open and laparoscopic procedures. In our cases series, 30 cases after 10 cases of direct instruction by an experienced surgeon, were required to learn LADG in terms of operation time and blood loss. However, the number of lymph nodes retrieved and the frequency of postoperative complications were not influenced by the number of cases experienced. Our results suggest that direct instruction by an experienced surgeon and an effective training system may be useful in shortening the learning curve with respect to operation time and decrease the number of cases required to achieve competency in performing LADG.

Several reports have described training systems for LADG [24-26]. Nobune et al. [24] reported the usefulness of their training system that focused on understanding the laparoscopy-specific anatomy for gastrectomy and the standardization of laparoscopic gastrectomy. They concluded that their training system, based on attaining adequate experience as both assistant and scopist, was effective in ensuring the clinical safety of laparoscopic gastrectomy performed by a trainee with the assistance of experienced surgeons. In another study on LADG training, trainees could perform laparoscopyassisted gastrectomy safety in a high-volume center with an established educational system, without the learning curve effect in intraoperative bleeding, the number of retrieved lymph nodes, and postoperative morbidity. In contrast, Yang et al. [26] reported an early experience of LADG at a low-volume center, concluding that laparoscopic gastrectomy can be performed safety at lowvolume center, but that an experienced surgical team and careful patient selection are necessary, and that to achieve early mastery of the learning curve for laparoscopic gastrectomy, surgeons need an effective education and training system. The learning curve for LADG may be influenced by many factors, and an effective training system must facilitate the introduction of LADG even in a low-volume center. The establishment of LADG training may contribute to improving patients' postoperative quality of life.
In conclusion, direct instruction to an inexperienced surgeon by a surgeon experienced in performing LADG is effective in decreasing the number of cases required to learn the procedure. Because LADG is more complex operation than the other laparoscopic procedures, an effective training system and standardization of LADG should be established.

\section{Disclosures}

Masashi Takemura, Katsuyuki Mayumi, Takashi Ikebe, Kayo Yoshida, Yushi Fujiwara and Sinya Tanimura have no conflicts of interest or financial ties to disclose.

\section{REFERENCES}

[1] M. Sasako, M. Saka, T. Fukagawa, H. Katai and T. Sano, "Surgical Treatment of Advanced Gastric Cancer: Japanese Perspective,” Digestive Surgery, Vol. 24, No. 2, 2007, pp. 101-107. doi:10.1159/000101896

[2] M. Sasako, “Gastric Cancer Eastern Experience,” Surgical Oncology Clinics of North America, Vol. 21, No. 1, 2012, pp. 71-77. doi:10.1016/j.soc.2011.09.013

[3] S. Kitano, K. Shimoda, M. Miyahara, N. Shiraishi, T. Bandoh, T. Yoshida, K. Shuto and M. Kobayashi, "Laparoscopic Approaches in the Management of Patients with Early Gastric Carcinomas,” Surgical Laparoscopy Endoscopy \& Percutaneous Techniques, Vol. 5, No. 5, 1995, pp. 359-362.

[4] H. Katai, M. Sasako, H. Fukuda, K. Nakamura, N. Hiki, M. Saka, H. Yamaue, T. Yoshikawa and K. Kojima, "Safety and Feasibility of Laparoscopy-Assisted Distal Gastrectomy with Suprapancreatic Nodal Dissection for Clinical Stage I Gastric Cancer: A Multicenter Phase II Trial (JCOG 0703)," Gastric Cancer, Vol. 13, No. 4, 2010, pp. 238-244. doi:10.1007/s10120-010-0565-0

[5] K. Nakamura, H. Katai, J. Mizusawa, T. Yoshikawa, M. Ando, M. Terashima, S. Ito, M. Takagi, A. Takagane, M. Ninomiya, N. Fukushima and M. Sasako, "A Phase III Study of Laparoscopy-Assisted versus Open Distal Gastrectomy with Nodal Dissection for Clinical Stage IA/IB Gastric Cancer (JCOG0912)," Japanese Journal of Clinical Oncology, Vol. 43, No. 3, 2013, pp. 324-327. doi:10.1093/jjco/hys220

[6] S. Tanimura, M. Higashino, Y. Fukunaga, M. Takemura, Y. Tanaka, Y. Fujiwara and H. Osugi, "Laparoscopic Gastrectomy for Gastric Cancer: Experience with More than 600 Cases," Surgical Endoscopy, Vol. 22, No. 5, 2008, pp. 1161-1164. doi:10.1007/s00464-008-9786-2

[7] K. Koeda, S. Nishizuka and G. Wakabayashi, "Minimally Invasive Surgery for Gastric Cancer: The Future Standard of Care,” World Journal of Surgery, Vol. 35, No. 7, 2011, pp. 1469-1477. doi:10.1007/s00268-011-1051-5

[8] H. H. Kim, S. U. Han, M. C. Kim, W. J. Hyung, W. Kim, H. J. Lee, S. W. Ryu, G. S. Cho, C. Y. Kim, H. K. Yang, J. do Park, K. Y. Song, S. I. Lee, S. Y. Ryu and J. H. Lee, "Prospective Randomized Controlled Trial (Phase III) to 
Comparing Laparoscopic Distal Gastrectomy with Open Distal Gastrectomy for Gastric Adenocarcinoma (KLASS 01)," Journal of the Korean Surgical Society, Vol. 84, No. 2, 2013, pp. 123-130. doi:10.4174/jkss.2013.84.2.123

[9] S. Tanimura, M. Higashino, Y. Fukunaga, S. Kishida, A. Ogata, Y. Fujiwara and H. Osugi, "Respiratory Function after Laparoscopic Distal Gastrectomy-An Index of Minimally Invasive Surgery,” World Journal of Surgery, Vol. 30, No. 7, 2006, pp. 1211-1215. doi:10.1007/s00268-005-0115-9

[10] Y. K. Zeng, Z. L. Yang, J. S. Peng, H. S. Lin and L. Cai, "Laparoscopy-Assisted versus Open Distal Gastrectomy for Early Gastric Cancer: Evidence from Randomized and Nonrandomized Clinical Trials,” Annals of Surgery, Vol. 256, No. 1, 2012, pp. 39-52. doi:10.1097/SLA.0b013e3182583e2e

[11] Y. W. Kim, Y. H. Baik, Y. H. Yun, B. H. Nam, D. H. Kim, I. J. Choi and J. M. Bae, "Improved Quality of Life Outcomes after Laparoscopy-Assisted Distal Gastrectomy for Early Gastric Cancer: Results of a Prospective Randomized Clinical Trial,” Annals of Surgery, Vol. 248, No. 5, 2008, pp. 721-727. doi:10.1097/SLA.0b013e318185e62e

[12] S. Kitano, N. Shiraishi, I. Uyama, K. Sugihara and N. Tanigawa, "A Multicenter Study on Oncologic Outcome of Laparoscopic Gastrectomy for Early Cancer in Japan,” Annals of Surgery, Vol. 245, No. 1, 2007, pp. 68-72. doi:10.1097/01.sla.0000225364.03133.f8

[13] S. W. Lee, E. Nomura, G. Bouras, T. Tokuhara, S. Tsunemi and N. Tanigawa, "Long-Term Oncologic Outcomes from Laparoscopic Gastrectomy for Gastric Cancer: A Single-Center Experience of 601 Consecutive Resections," Journal of the American College of Surgeons, Vol. 211, No. 1, 2010, pp. 33-40. doi:10.1016/j.jamcollsurg.2010.03.018

[14] S. Y. Kang, S. Y. Lee, C. Y. Kim and D. H. Yang, “Comparison of Learning Curves and Clinical Outcomes between Laparoscopy-Assisted Distal Gastrectomy and Open Distal Gastrectomy,” Gastric Cancer, Vol. 10, No. 4, 2010, pp. 247-253. doi:10.5230/jgc.2010.10.4.247

[15] M. C. Kim, G. J. Jung and H. H. Kim, "Learning Curve of Laparoscopy-Assisted Distal Gastrectomy with Systemic Lymphadenectomy for Early Gastric Cancer," World Journal of Gastroenterology, Vol. 11, No. 47, 2005, pp. 7508-7511.

[16] C. Kunisaki, H. Makino, N. Yamamoto, T. Sato, T. Oshima, Y. Nagano, S. Fujii, H. Akiyama, Y. Otsuka, H. A. Ono, T. Kosaka, R. Takagawa and H. Shimada, "Learning Curve for Laparoscopy-Assisted Distal Gastrectomy with Regional Lymph Node Dissection for Early Gastric Cancer," Surgical Laparoscopy Endoscopy \& Percutaneous Techniques, Vol. 18, No. 3, 2008, pp. 236241. doi:10.1097/SLE.0b013e31816aa13f

[17] X. Zhang and N. Tanigawa, "Learning Curve of Laparoscopic Surgery for Gastric Cancer, a Laparoscopic Distal Gastrectomy-Based Analysis,” Surgical Endoscopy, Vol.
23, No. 6, 2009, pp. 1259-1264. doi:10.1007/s00464-008-0142-3

[18] M. Tokunaga, N. Hiki, T. Fukunaga, A. Miki, S. Ohyama, S. Miyata and T. Yamaguchi, "Learning Curve of Laparoscopy-Assisted Gastrectomy Using a Standardized Surgical Technique and an Established Educational System," Scandinavian Journal of Surgery, Vol. 100, No. 2, 2011, pp. 86-91.

[19] Japanese Gastric Cancer Association, “Japanese Classification of Gastric Carcinoma: 3rd English Edition,” Gastric Cancer, Vol. 14, No. 2, 2011, pp. 101-112. doi:10.1007/s10120-011-0041-5

[20] P. A. Clavien, J. Barkun, M. L. de Oliveira, J. N. Vauthey, D. Dindo, R. D. Schulick, E. de Santibañes, J. Pekolj, K. Slankamenac, C. Bassi, R. Graf, R. Vonlanthen, R. Padbury, J. L. Cameron and M. Makuuchi, "The ClavienDindo Classification of Surgical Complications: FiveYear Experience," Annals of Surgery, Vol. 250, No. 2, 2009, pp. 187-196. doi:10.1097/SLA.0b013e3181b13ca2

[21] Y. Ezoe, M. Muto, N. Uedo, H. Doyama, K. Yao, I. Oda, K. Kaneko, Y. Kawahara, C. Yokoi, Y. Sugiura, H. Ishikawa, Y. Takeuchi, Y. Kaneko and Y. Saito, "Magnifying Narrowband Imaging Is More Accurate Than Conventional White-Light Imaging in Diagnosis of Gastric Mucosal Cancer,” Gastroenterology, Vol. 141, No. 6, 2011, pp. 2017-2025. doi:10.1053/j.gastro.2011.08.007

[22] Y. Tsuji, K. Ohata, M. Sekiguchi, A. Ohno, T. Ito, H. Chiba, T. Gunji, J. Fukushima, N. Yamamichi, M. Fujishiro, N. Matsuhashi and K. Koike, "Magnifying Endoscopy with Narrow-Band Imaging Helps Determine the Management of Gastric Adenomas,” Gastric Cancer, Vol. 15, No. 4, 2012, pp. 414-418. doi:10.1007/s10120-011-0133-2

[23] E. Otsuji, A. Toma, S. Kobayashi, H. Cho, K. Okamoto, A. Hagiwara and H. Yamagishi, "Long-Term Benefit of Extended Lymphadenectomy with Gastrectomy in Distally Located Early Gastric Carcinoma," The American Journal of Surgery, Vol. 180, No. 2, 2000, pp. 127-132. doi:10.1016/S0002-9610(00)00436-0

[24] S. Nunobe, N. Hiki, S. Tanimura, K. Nohara, T. Sano and T. Yamaguchi, “The Clinical Safety of Performing Laparoscopic Gastrectomy for Gastric Cancer by Trainees after Sufficient Experience in Assisting," World Journal of Surgery, Vol. 37, No. 2, 2013, pp. 424-429. doi:10.1007/s00268-012-1827-2

[25] M. Tokunaga, N. Hiki, T. Fukunaga, A. Miki, S. Ohyama, S. Miyata and T. Yamaguchi, "Learning Curve of Laparoscopy-Assisted Gastrectomy Using a Standardized Surgical Technique and an Established Educational System," Scandinavian Journal of Surgery, Vol. 100, No. 2, 2011, pp. 86-91.

[26] S. J. Yang, E. J. Ahn, S. H. Park, J. H. Kim and J. M. Park, "The Early Experience of Laparoscopy-Assisted Gastrectomy for Gastric Cancer at a Low-Volume Center,” Gastric Cancer, Vol. 10, No. 4, 2010, pp. 241-246. doi:10.5230/jgc.2010.10.4.241 